\title{
Problematizando el discurso biológico sobre el cuerpo y género, y su influencia en las prácticas de enseñanza de la biología
}

\author{
Yonier Alexander Orozco Marin' (iD 0000-0002-4095-4875 \\ 'Universidade Federal de Santa Catarina, Florianópolis, SC, Brasil. 88040-900 - \\ yonier.orozco.marin@posgrad.ufsc.br
}

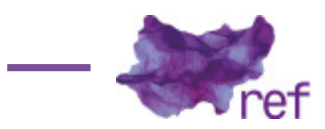

\begin{abstract}
Resumen: El ensayo tiene como tesis central reconocer la necesidad de problematizar el discurso biológico sobre género y el cuerpo, y su circulación en los contextos escolares como un conocimiento científico neutro y objetivo basado en la suposición de género normalizado y cuerpo ideal que ubica a los cuerpos diferentes, extraños, al margen. Inicialmente se discuten los conceptos de cuerpo ideal y de cuerpos al margen. Seguidamente se ofrece una serie de argumentos que justifican la necesidad de problematizar ese discurso biológico. Finalmente se discuten posibles caminos y rutas para esa problematización, recurriendo a presupuestos teóricos de la decolonialidad, aportando algunas reflexiones específicas para la enseñanza de la biología. El ensayo discute significaciones ideológicas y colonizadas que permean y fundamentan el discurso biológico.
\end{abstract}

Palabras clave: conocimiento biológico; cuerpo; educación sexual; género.

Problematizando o discurso biológico sobre o corpo e gênero, e sua influência nas práticas de ensino da biologia

Resumo: O ensaio tem como propósito central reconhecer a necessidade de problematizar o discurso biológico sobre gênero e corpo, e sua circulação nos contextos escolares como um conhecimento científico neutro e objetivo, baseado no pressuposto de gênero normalizado e corpo ideal, que localiza aos corpos diferentes, estranhos, na margem. Inicialmente, os conceitos de corpo ideal e corpos nas margens são discutidos. Logo, uma série de argumentos que justificam a necessidade de problematizar esse discurso biológico é oferecida. Por fim, são discutidos possíveis caminhos para essa problematização, utilizando pressupostos teóricos da decolonialidade, fornecendo algumas reflexões específicas para o ensino da biologia. O ensaio discute significados ideológicos e colonizados que permeiam e fundamentam o discurso biológico.

Palavras-chave: conhecimento biológico; corpo; educação sexual; gênero.

Problematizing the Blological Discourse about the Body and Gender, and its Influence on the Teaching Practices of Biology

Abstract: This essay has as a central thesis to recognize the need to problematize the biological discourse on gender and the body and its circulation in school contexts as a neutral and objective knowledge, based on the assumption of ideal body that locates the different, strange bodies, at the margin. Initially, the concepts of ideal body and bodies at the margin are discussed. Then, a series of arguments that justify the need to problematize this biological discourse is offered. Finally, possible paths and routes for this problematization are discussed, resorting to theoretical assumptions of decoloniality, providing some specific reflections for the teaching of biology. The essay discusses ideological and colonized meanings that permeate and base the biological discourse.

Keywords: Biological knowledge; Body; Gender; Sex education. 


\section{Introducción}

Me permitiré comenzar este ensayo mencionando que cualquier práctica educativa, antes que cualquier otra cosa, es una práctica cultural de procesos de constitución identitaria, permeada y fundamentada en significantes de modernidad, género, raza, etnia, discapacidad y diversidad social. De la misma manera, la producción del conocimiento-discurso biológico occidental es también una práctica cultural e histórica permeada y fundamentada también por esos significantes.

La propuesta de este ensayo consiste en construir reflexiones sobre la necesidad de problematizar el discurso biológico sobre cuestiones de género y sexualidad, sobre el cuerpo ideal y su influencia en las prácticas de educación sexual y de enseñanza de la biología, consideradas neutras y objetivas, pero que, en realidad, son fundamentadas en binarismos y normalizaciones que generan exclusiones. Para ello, en primer lugar, abordaré la cuestión del "cuerpo ideal" y cuerpos al margen desde el discurso biológico, para posteriormente ofrecer una serie de argumentos sobre la importancia de problematizar ese discurso biológico, principalmente en el ámbito escolar. Finalmente, intento mostrar algunas bases para nuevos caminos (no recetas) que nos permitan nuevas interpretaciones y escritas del discurso biológico sobre cuestiones de género y sexualidad, aportando algunas reflexiones específicas para la enseñanza de la biología.

\section{Cuerpos ideales y cuerpos al margen desde el discurso biológico}

La biología, asumida como una ciencia que estudia lo vivo, entendiendo lo vivo como lo vivo orgánico, se fundamenta en el paradigma de cuerpos preexistentes sobre los cuales su principal tarea es construir conocimientos neutros y objetivos. Sobre esta cientificidad, normalmente se asume el discurso biológico sobre el cuerpo, o por lo menos, así es tradicionalmente presentado, como un conjunto de conocimientos libre de interferencias históricas, políticas y sociales que tienen correspondencia con una realidad material. Sin embargo, lo biológico y lo histórico no constituyen una secuencia en la que lo uno produce lo otro. Entre esos discursos existe una complejidad creciente manifestada principalmente en las tecnologías modernas de poder que toman como objetivo al cuerpo (Michel FOUCAULT, 1999).

En la propuesta de este ensayo, tomo la postura de asumir lo biológico como un discurso, más que un conjunto de conocimientos científicos. Asumirlo como discurso implica comprenderlo como producción humana que está permeada de diversos significantes de poder, identidad, género, raza, etnia, discapacidad. Así, por ejemplo, en la atomización de lo vivo, organizado en niveles jerárquicos (molecular, celular, pluricelular, organismos y ecosistemas), no solo se está dando significado, como se pretende, a un cuerpo orgánico, también se instalan y se reconstruyen encada nivel la metáfora heterosexual como matriz única de inteligibilidad (Beatriz PRECIADO, 2008).

Según Foucault (1999), diversos dispositivos de poder se articulan directamente al cuerpo, a sus procesos biológicos y placeres. Por lo tanto, podríamos sospechar que la matriz heterosexual rige el discurso biológico sobre el cuerpo, y que las significaciones binarias de género que fundamentan la biología se configuran como dispositivo de poder que construye el cuerpo padrón, normal o ideal (blanco, heterosexual, saludable y sin discapacidad alguna) y localiza otros cuerpos como las excepciones, las anomalías, los extravagantes, o los enfermos.

Considero importante colocar foco en el análisis crítico de los significantes de género que sustentan el discurso biológico, sin desconocer que el concepto significante de género apareció inicialmente al servicio de y limitado por el sistema binario heterosexual. Sin embargo, este concepto y otros como raza, etnia, clase social o discapacidad pueden ser utilizados y repetidos en direcciones diferentes que trasladan e invierten sus propósitos iniciales (Judith BUTLER, 1993). De esa manera, el análisis, podría arriesgarme a denominarlo decolonial, de las cuestiones de género que fundamentan el discurso biológico podría brindarnos herramientas conceptuales para denunciar reduccionismos y normalizaciones trasladas a los contextos escolares, disfrazados de buenas intenciones en el marco de la educación sexual y la educación para la salud, y en la enseñanza de conceptos biológicos que aparentemente no tienen nada que ver con cuestiones de género y sexualidad.

Es importante problematizar el discurso biológico en el contexto de las prácticas educativas, pues el discurso biológico se configura como contenido obligatorio y a la vez como herramienta con la cual se instala en los sujetos la idea del binarismo sexual y cultural del cuerpo ideal. Discurso que en muchos casos no permite ser discutido, pues es presentado como verdad científica, y todos los silenciamientos y pasividades que eso significa.

Dar al discurso biológico (y a sus normalizaciones-exclusiones) valor de verdad científica irrefutable ha generado que en la escuela, particularmente desde la enseñanza dela biología, circulen suposiciones vehiculadas por las/los profesoras/es, como las siguientes: a) Los sujetos van a modificar sus comportamientos y sus prácticas a la luz de conocimientos biológicos transmitidos; b) Existe un lenguaje científico que permite dar un nombre neutral a los órganos y sus funciones, 
desconsiderando las emociones y sentidos del propio sujeto; c) Existen preguntas de opinión (generalmente las de las/los estudiantes) que son diferentes de las preguntas científico-académicas (generalmente las del/a profesor/a), las últimas deben ser privilegiadas para garantizar la neutralidad del conocimiento biológico (Gabi DÍAZ; Graciela MORGADE; Cecilia ROMÀN, 201 1). Es decir, la circulación del discurso biológico no problematizado en las escuelas, además de garantizar la instalación como verdad científica del binarismo de género, también excluye al sujeto y sus intereses del propio proceso de significación de su cuerpo.

Cuando los sujetos asumen identidades o roles en la escuela que no se corresponden con los binarismos de género instalados por los discursos biológicos sobre el cuerpo, aparece lo que puede ser denominado de pánico pedagógico. La presencia de estos grupos es profundamente perturbadora en el campo educacional (Guacira LOURO, 2010), presencia sobre la cual se activan una serie de acciones escolares, acciones de poder normalizadoras (orientación psicológica, vigilancia permanente, silenciamientos), que en el fondo siempre se fundamentan en el discurso biológico del cuerpo ideal y en el binarismo de género. Esa normalización sigue la orden y el padrón heterosexual, que excluye otras posibilidades de experiencias, conduciendo grupos humanos como los homosexuales, bisexuales, lesbianas, personas intersexo y las transidentidades a situaciones de vulnerabilidad social, cultural y de poder (Paula COSTA; Joanalira CORPES; Elenita SILVA; Teresa VILAÇA, 2016).

Me atrevo a complementar a las autoras, agregando que esa normalización sigue la orden y padrón de un cuerpo ideal, un cuerpo no preexistente, sino que construido por las ciencias biológicas y otras ciencias. En el discurso de esas ciencias, a veces más implícitamente que explícitamente, el cuerpo que se construye es generalmente un cuerpo masculino, blanco, heterosexual, completo, sin ninguna discapacidad y sano, dando lugar a los cuerpos que no encajan en ese padrón, de cuerpos al margen o cuerpos no modelo en menor o mayor medida, los otros.

Esta situación se evidencia en diversos momentos y espacios de la producción del conocimiento biológico y su enseñanza. Desde las representaciones del cuerpo en libros didácticos que generalmente representan un modelo masculino, blanco, sano y completo, y donde la mujer solo aparece cuando debe destacarse el binarismo, la reproducción, la diferencia genital y hormonal entre ambos.

El libro didáctico, los medios de comunicación, los congresos científicos, funcionan así como unas de las tantas herramientas de exclusión, donde identidades sexuales diversas, la/el discapacitada/o, las personas con trisomía en el par cromosómico 21, e incluso las/los afrodescendientes y las/los pobres, aparecen siempre asociados a significantes de síndromes, anomalías, excepciones a la regla, deficiencias congénitas, analfabeta/o- esclava/o, fracaso, enfermas/os, producto de un problema psicológico que no siguió el orden biológico, sujetos que somos obligados a aceptar, pero nunca como modelo de cuerpo ideal.

Siguiendo esa línea, considero que en la escuela también se construyen los cuerpos, pues insisto, el cuerpo no es únicamente ese algo orgánico preexistente sobre el cual la biología y ciencias afines dicen algo. En la escuela, aquellos que se empadronan en el binarismo sexual y cultural de la biología son dotados de privilegios, y aquellos que no, ganan el lugar de cuerpos que no importan (o a los que no se les debe dar tanta importancia), o de cuerpos que deben ser corregidos, invisibilizados (BUTLER, 1993). Por ejemplo, la educación sexual asume la heterosexualidad como norma obligatoria en las aulas cuando reafirma reiteradamente el discurso de prevención del embarazo, asumiendo que todas/os las/los alumnas/os sienten atracción sexual por el sexo opuesto. Las relaciones homoafectivas son raramente abordadas en la educación sexual y en la enseñanza de la biología. Según Marcio Caetano, Treyce Goulart y Marlon Silva (2016), esto se debe principalmente a que la heteronormatividad, como norma social, no solo pretende mantener y reforzar una lógica presentada como natural, que crea una dicotomía complementar entre mujeres y hombres, sino que también contribuye a la degradación social de las personas que transgreden esa norma. La enseñanza de la biología se constituye, entonces, como dispositivo para administrar las identidades de los sujetos en los contextos escolares, instalando y reforzando la heteronorma como único camino legítimo, normal, o natural.

Con esto no quiero decir que temas como homosexualidad y travestilidad nunca son abordados en la escuela, particularmente en la enseñanza de la biología. Por el contrario, pienso que se habla mucho sobre ellos, solo que en situaciones diferentes y con sentidos diferentes. Generalmente cuando la/el profesor/a o la/el alumna/o hacen referencia a algo raro, a algo que debe ser evitado o que es perverso o perturbador. No es un tema que aparezca en los libros didácticos de biología, pero sí puede aparecer en los comentarios de los alumnos en el aula, en los chistes o apodos para hacerle bullying a otros, en las salas de profesores cuando se habla sobre las/los estudiantes.

Se repiten discursos performativos que buscan normalizar. Al colocar esos asuntos en el plano discursivo, la sexualidad es administrada por los dispositivos de poder (FOUCAULT, 1999). 
Dispositivos por los cuales la homosexualidad y otras identidades son interpretadas y armonizadas utilizando el mismo cuadro conceptual que es utilizado para la heterosexualidad (Giovanni DALL'ORTO, 1990), asignándoles un lugar periférico de extraños, problemas, aberraciones, lo que no se encaja y perturba.

Es importante recordar la obra coordinada por Morgade (2011), titulada: "Toda educación es sexual, hacia una educación sexuada justa". En esta obra se defiende que en todos los procesos educativos de todos los niveles y de todas las áreas, entre ellas y especialmente la biología, se procesan significaciones de género que construyen cuerpos sexuados. Siguiendo esa línea, podríamos pensar que se pueden mantener las significaciones binarias de género que excluyen y colocan al otro en las márgenes, en la posición desprivilegiada, o podemos escoger identificar otras posibilidades discursivas, otros discursos biológicos que asumen su no objetividad, fundamentados en otras significaciones de género, raza, etnia, discapacidad y clase social.

\section{¿Por qué problematizar el discurso biológico que circula en los espacios escolares?}

Para justificar la necesidad de esta problematización, se debe reconocer a la escuela dentro de estructuras y relaciones de poder, como institución privilegiada para administrar las identidades de los sujetos, filtrando discursos, a través de actos performativos sustentados en la idea de un sujeto ideal, o como acostumbramos a decir, la/el ciudadana/o ideal. La educación escolarizada como maquinaria de poder donde ocurren interrelaciones en las cuales el cuerpo es inventado, tramado, engendrado, en medio de otras invenciones y modos de ser y existir (Elenita SILVA, 2014).

La escuela como un dispositivo de administración de identidades, donde el abordaje explícito de las cuestiones de género y sexualidad es tratado como tema extra, la novedad, otro asunto más o incluso un problema. Las cuestiones de género y sexualidad han ganado una posición meramente complementaria en la escuela, y no una posición de significantes estructurantes de los discursos y prácticas del cotidiano escolar. Eso cuando tratadas explícitamente, pues en algunos casos, escuelas y profesores pueden determinar qué temas sobre sexualidad, por su supuesta dimensión subjetiva, no deberían ser abordados en un contexto público como lo es la escuela (MORGADE, 2015).

Particularmente en la enseñanza de la biología esa situación es más evidente, pues las cuestiones de género y sexualidad se relegan a la educación sexual y la educación para la salud que generalmente ocupan un lugar complementario en los currículos, desde una perspectiva meramente preventiva, higienizante y anatómica, que deja intacto al propio discurso biológico y los significantes de género, discapacidad, raza y etnia que lo fundamentan.

La ausencia de una postura crítica sobre el conocimiento biológico también se evidencia en algunos trabajos, en el desarrollo de investigaciones sobre educación sexual y educación para la salud, que colocan el énfasis en el contexto familiar de los alumnos (Verónica LUISI, 2013), su situación social y sus conocimientos previos presentados generalmente como obstáculos o insuficientes (Deisy CARDONA; Alejandra ARIZA; Cindy GAONA; Óscar MEDINA, 2015), pero que escasamente discuten el propio discurso biológico que circula en la escuela sobre género, sexualidad y cuerpo. También se puede evidenciar en lo poco que las cuestiones de género y sexualidad se han incluido o abordado en las propuestas del conocimiento profesional del profesor de biología, salvo algunos trabajos como el de María Plaza, Leonardo González y Elsa Meinardi (2015), en el cual se destaca que las creencias del profesorado sobre género conforman y atraviesan el conocimiento profesional, especialmente el conocimiento del contenido. Estos autores también reconocen que estas creencias pocas veces son explicitadas y se manifiestan en las clases a través del currículo oculto.

Con una escasa problematización de ese discurso biológico, las prácticas propiciadas por parte de saberes como la medicina, la psicología y las ciencias de la educación, entre otras, buscan que los sujetos conozcan y cuiden su cuerpo a través de prácticas ligadas a la prevención - la planificación, esta última como una responsabilidad atribuida casi que en su totalidad a la mujer (Claudia JARAMILLO; Deysi SERRATO, 2016). Estoy de acuerdo con las autoras y me atrevo a complementarlas, destacando que particularmente en la enseñanza de la biología que se basa en un discurso biológico no problematizado sobre el cuerpo, no sólo se espera que el sujeto conozca y cuide su cuerpo, sino que, y principalmente, se espera que lo conozca a través de la perspectiva binaria de género desde la cual se fundamenta la biología, y que lo cuide (o lo normalice, lo higienice) de acuerdo a lo establecido por la biología como cuerpo ideal. Un cuerpo sano, completo, de preferencia blanco y heterosexual, desconsiderando las particularidades ecológicas, políticas, sociales, económicas, culturales e históricas que se entrelazan en los diversos contextos donde se enseña biología, principalmente en un país de tanta biodiversidad cultural y social como lo es Colombia, y en general, los países de América Latina.

En este contexto, la/el profesor/a de biología adquiere un papel fundamental, pues aquello que debe ser enseñado es una decisión que toman las/los profesionales técnicos del campo de la 
política curricular central. Sin embargo, lo que es enseñado en cada escuela o clase es otro nivel de decisión, en el cual las significaciones, deseos, discursos y saberes de las/los profesoras/es tienen una influencia mayor (DÍAZ; MORGADE; ROMÀN, 2011).

Así, en el contexto del aula, la/el profesor/a de biología puede ser el agente que utiliza el discurso biológico y lo dota de cientificidad, objetividad, presentándolo como un espejo de la realidad orgánica de los cuerpos, asumida indiscutiblemente como heterosexual. En nombre de un pretencioso carácter dicho científico, reproduce una estructura de poder en la cual el discurso biológico posiciona, opera, esencializa, fija, endereza y coloca en funcionamiento la repetición/ reproducción de un camino binario para el cuerpo, género y sexualidad (Sandro SANTOS; Ronaldo ARAUJO, 2015). Discurso cargado de valores que son considerados masculinos, pues en la biología, como en otras ciencias occidentales, la racionalidad, la objetividad y el carácter impersonal son presentados como opuestos al modo de pensar personal, emocional y subjetivo, supuestamente femenino (Eulalia PÉREZ, 1996).

También, la/el profesor/a puede utilizar ese discurso biológico como vehículo para impregnar de cientificidad, concepciones de género que ha construido en su experiencia de vida realizando, por ejemplo, propaganda cristiana a través de la biología, negando la existencia de individuos homosexuales, alegando que existen apenas actos-conductas homosexuales y no personas como tal (DALL'ORTO, 1990).

En otros casos, la/el profesor/a, precisamente por su experiencia de vida, puede tomar la iniciativa de reflexionar y proponer otras prácticas educativas que no se fundamenten en exclusiones y colocación de cuerpos al margen. Sin embargo, esa/e profesor/a tropieza con un discurso biológico que camina en otra vía. Sumando a eso, el escaso o nulo abordaje que tuvo su formación inicial sobre el abordaje no normalizador de las identidades sexuales en la escuela. Incluso, y precisamente por esa falta de formación, la/el profesor/a puede estar utilizando los cuadros conceptuales de la heterosexualidad, a pesar de que con sus acciones quiera conseguir otros resultados. Como mencionan Santos y Araujo (2015), cuando las/los profesoras/es entran en contacto con otros discursos sobre el cuerpo, ocurren extrañamientos, descubrimientos, desterritorializaciones, angustias, conflictos (in)certezas, (des)esencializaciones.

Justifico la necesidad de estudiar estas cuestiones, pues también es importante reconocer que, a pesar de ser recientemente, otros autores, otras/os científicas/os de la biología están construyendo otros discursos biológicos sobre el cuerpo. Uno de los casos puede ser encontrado en Siddhartha Mukherjee, indiano y uno de los principales estudiosos del cáncer a nivel mundial. En su libro más reciente, The Gene: an Intimate History, el autor define género como un espectro continuo (y no binario), resultado de la integración de insumos genéticos, del medio ambiente, de hormonas, de comportamientos, exposiciones, desempeño social, roles culturales y memoria (MUKHERJEE, 2016).

Es una definición que cuestiona los binarismos desde los cuales se fundamentan los estudios biológicos sobre sexo, género y sexualidad. Sin embargo, sospecho que discursos como estos demorarán en circular en las universidades y en las escuelas, no únicamente porque los nuevos saberes producidos por las/los científicas/os normalmente demoran en llegar a los contextos educativos, sino también porque debemos considerar que Mukherjee es un científico no blanco, no estadounidense, no europeo. A pesar de que pocas veces lo reconocemos, ese imaginario de que actualmente la información y el conocimiento circulan libre y globalmente no es totalmente verdadero. Como ya mencioné, nuestros significantes de raza, género, discapacidad y clase social condicionan nuestras selecciones de discurso y nos indican aquellos que son dignos de ser respetados, valorizados y aprendidos.

No es casualidad que los saberes de las comunidades indígenas sobre el cuerpo, la biodiversidad, la vida, sean tan escasamente integrados al currículo de ciencias naturales, y cuando lo son, ganen un lugar de saber popular o conocimiento tradicional, lenguaje a través del cual inevitablemente se esconde una jerarquía que lo coloca como inferior. Lo mismo suele acontecer con los conocimientos que traen las/los estudiantes.

En mi formación inicial siempre me cuestioné, por ejemplo, porque si consideramos a las/los asiáticas/os tan inteligentes e innovadoras/es en el área científica, nunca me presentaron avances científicos de esos países, nunca tuve la oportunidad de leer algún libro de algún de esas/os autoras/es, o de conocer como fue la historia del desarrollo del conocimiento biológico en esa región. La biología que circula en nuestras escuelas es una biología occidental (europea y estadunidense), con todas las significaciones de género, raza, etnia, clase social y discapacidad que la han permeado históricamente en el contexto de occidente.

Lo anterior equivale a mencionar, con todas las controversias que esto levanta, que cualquier contenido (discurso) biológico, como fotosíntesis, herencia genética, meiosis, relaciones ecológicas, en fin, cualquier contenido, por más objetivo y neutro que parezca, también en sus raíces y superficies está atravesado por significantes de género, raza, discapacidad y clase social desde el lugar geo-político y cuerpo-político de la persona que lo produce, lo incorpora a un currículo, lo enseña, lo aprende. 
La epistemología de la biología ha permitido avances importantísimos en reconocer, tanto en los contextos académicos como en los contextos escolares, que la/el científica/o y quien enseña ocupan un contexto histórico y un lugar geo-político que condiciona los discursos-conocimientos que produce y que condiciona lo que se considera verdadero. Sin embargo, como menciona Morgade (2015), a pesar de que la categoría cuerpo docente ha sido utilizada por décadas para referirse al equipo de docentes de una región o escuela, reconocer que quien enseña tiene un cuerpo (en el cual vale la pena reparar), es un eje relativamente reciente en los estudios sobre trabajo docente.

Meinardi (2016) nos refresca sobre este aspecto mencionando que las/los profesoras/es, que ahora deben encargarse de estos temas en el aula (por lo menos explícitamente, pues implícitamente el binarismo de género y la noción de cuerpo ideal vienen siendo instalados históricamente en la escuela), vinculan aspectos de su biografía escolar, su trayectoria profesional y sus creencias personales, que pueden verse reflejadas en el currículo oculto. Me permito agregar que esos aspectos no solo influencian la práctica de enseñanza del/a profesor/a, sino que también construyen el propio cuerpo del/a profesor/a y lo permean de significaciones y normalizaciones, con las cuales tendrá que cargar, y sobre las cuales tendrá que reafirmar, reflexionar, o reconstruir discursos cuando enseña.

Reconocer que quien produce conocimiento, que quien formula el currículo, que quien enseña y aprende lo hace desde un lugar cuerpo-político, significa desmantelar el Ego no situado y ubicar esos discursos en un locus de enunciación, en un lugar epistémico étnico/racial/sexual/de género de los sujetos enunciadores (Ramón GROSFOGUEL, 2008).

Es importante reconocer las relaciones sociales que componen la esfera de lo simbólico del cuerpo, el género y la sexualidad en los discursos académicos que seleccionamos y privilegiamos. Sospecho, al igual que Butler (1993), que esos discursos ganan apariencia de ley en una economía heterosexual, que al mismo tiempo determina lo que está por fuera de la ley, contribuyendo a hacerlo biológica y culturalmente inviable. Son pocos los esfuerzos que se han realizado por construir, reconstruir, reinterpretar el discurso biológico desde una visión que ultrapase lo biomédico, lo binario y la matriz heterosexual (COSTA; CORPES; SILVA; VILAÇA, 2016).

De esa manera, cuando la ciencia biológica y la disciplina biología y su enseñanza, principalmente a través de la educación sexual y para la salud, asumen la lógica anatómica del cuerpo, participan de la invención de un cuerpo que convence a todos del mito de la identidad única, fija e inmutable del organismo/cuerpo humano, haciendo desaparecer la diferencia (SILVA, 2014), dándole el lugar de la anomalía, lo extraño.

Siguiendo esa línea, traigo la siguiente afirmación: el cuerpo también es inventado y construido, no es exclusivamente una realidad orgánica sobre la cual la biología funciona como espejo para significarlo. Sobre este punto, es importante considerar conceptos como el de somatechnics (Joseph PUGLIESE; SUsan STRYKER, 2009) que enuncian que la concretización del cuerpo es siempre biocultural, por lo tanto, no puede ser reducida al ámbito meramente físico-anatómico, pero también no puede ser totalmente desmaterializado como un fenómeno meramente discursivo.

\section{¿Posibles caminos? ¿Posibles rutas para esa problematización?}

Probablemente la/el lector/a quedará con molestia al saber que para problematizar el discurso biológico sobre género y sexualidad y su influencia en la enseñanza de la biología existen varios caminos, pero no recetas o técnicas. Considero que cualquiera de esos caminos estará lleno de contradicciones, obstáculos, miedos, pero, sobre todo, debe estar orientado por una tendenciosa postura política del/a docente que se aleje del paradigma de la objetividad, del silenciamiento de los sujetos. No son caminos ya existentes por los cuales debemos transitar, son caminos que debemos imaginar y construir a través de nuestra práctica reflexiva.

Traigo aquí la propuesta de saber con sabor (Durval ALBUQUERQUE, 2014), desde la cual nuevas escritas, nuevos discursos, y considero que entre ellos los discursos-contenidos biológicos que circulan en las escuelas, pueden salir de sus moldes positivistas y reconocer todas sus pasiones, juzgamientos político-ideológicos o de valor, su no imparcialidad, un saber-discurso sensible y con marca. Otras interpretaciones desde y sobre la biología, capaces de ayudarnos a reconstruir nuestros territorios existenciales, nuestras decisiones y nuestras experiencias (Gerson ALBUQUERQUE, 2016).

No se trata de restar importancia a la biología, o de estigmatizarla negativamente. Se trata de reconocer en ella pasiones, en reconocer su sabor. Se trata de entender que ese conocimiento biológico no se localiza en una caja aparte en nuestra mente, aislada e independiente de nuestras significaciones, estigmas y preconceptos más profundos, construidos como seres históricos y ontológicos.

Así, entenderíamos que no existe una definición totalmente neutra del concepto de fenotipo, por ejemplo. Definido tradicionalmente en libros escolares y por genetistas como las características observables de un ser vivo, sean físicas, bioquímicas o comportamentales, si nos proponemos 
ponerle sabor a ese concepto, encontraremos como en el plano discursivo de cualquier persona esas características observables no son dadas por el ser vivo al que observa en sí, y más bien son influenciadas por significantes de género, raza, clase social y discapacidad, que acaban determinando que resaltemos (a veces peyorativamente, a veces como algo gracioso y pasajero, y en otros casos incluso en contextos formales de enseñanza) características fenotípicas asociadas a un alto rendimiento sexual a personas de piel negra, que demos un lugar predeterminado a la mujer como cuidadora de hijos por sus características anatómicas, que consideremos menos problemático al gay que no muestra rasgos tan afeminados, o que cuando observamos una persona del universo de las transidentidades busquemos inmediatamente asociar sus características como femeninas o masculinas ¿Es hombre o mujer?

Debemos reconocer nuestra incapacidad de asociar los fenómenos biológicos con los fenómenos culturales, porque los consideramos necesariamente opuestos o de mundos distintos. Y cuando los juntamos, lo hacemos simulando una armonía y una relación aparentemente dialógica, mas que, en el fondo, no permite el cuestionamiento, ni la problematización de las significaciones de género, raza, etnia, discapacidad y clase social que fundamentan el proceso de producción del conocimiento biológico y su enseñanza.

Problematizar el discurso biológico no se trata simplemente de realizar otras escritas, otros discursos, desde los cuales se integre o se acepte al excéntrico, los cuerpos que el discurso biológico coloca en las márgenes como inviables. Pues el/la excéntrico/a simplemente no se opone al centro o espera ser reconocida/o, aceptada/o, tolerada/o por él, la/el excéntrica/o desea quebrar con una lógica que a favor o en contra continua se remetiendo, siempre, a la identidad central (LOURO, 2010). O sea, no se trata exclusivamente de construir discursos en los cuales el homosexual, la lesbiana, las transidentidades, las nuevas masculinidades y feminidades sean aceptadas o toleradas. Se trata sí, de construir otros discursos donde no es necesario diferenciar lo normal de lo anormal, lo representativo de la minoría, lo ideal de lo extraño.

Traigo las palabras de Paola Roa y Angélica Osorio (2016), en las cuales se destaca que la enseñanza debe trascender a la práctica misma, lo cotidiano y sus discursos hegemónicos, y aunque pasando por estos y por su reflexión, debemos mirar desde otros lados, desde otras relaciones, desde otros discursos, otras formas de asumirnos, de significarnos y de significar a las/los construidas/ os como otras/os. Particularmente desde el área de la biología y su enseñanza tenemos mucho por hacer, pues tenemos una tradición histórica de significaciones resistente a ser cuestionada. A través de esa problematización, tendremos muchos obstáculos, peros e incluso intimidaciones, sin embargo, en ese proceso encontraremos también posibilidades extraordinarias de construir otras realidades, de resignificarnos y de construir nuevas lógicas en que los cuerpos no son clasificados y jerarquizados.

Esos nuevos discursos o interpretaciones con saber-sabor pueden asumir un lugar subalterno, no por ser menos válidos o verdaderos que el discurso biológico tradicional y sí por representar un esfuerzo político para proveer otra gramática, otra epistemología, otras referencias que no sean siempre aquellas que aprendimos a ver como verdaderas, o únicas dignas de ser aprendidas (Larissa PELÚCIO, 2012).

\section{Reflexiones específicas para la enseñanza de la biología}

Debemos considerar que para hablar de género y sexualidad no debemos necesariamente estar tocando estos temas en sala de aula. Se trata de ser autorreflexivos y vigilantes de nuestras propias concepciones como profesoras/es. Considero que cuando tratamos temas como genotipo y fenotipo, fecundación, biodiversidad, cuerpo humano, anatomía y fisiología, cortejo en animales, por mencionar algunos, procesamos significaciones de género binarias y que excluyen las/os otras/os. De la misma manera, considero que es posible investigar sobre nuevas formas de enseñar estos conceptos desde otras percepciones sobre género y sexualidad.

Entiendo que en la enseñanza de la biología tenemos la necesidad de construir modelos y representaciones, pues abordamos fenómenos de alta heterogeneidad y diversidad. Entiendo que es necesario un modelo de célula animal o vegetal (las que tradicionalmente aparecen en los libros) para enseñar ese contenido, a pesar de que en la vida real exista una gran variedad de formatos celulares, variaciones, y tal vez difícilmente se encuentre una célula con todas las características con las que normalmente se representa la célula.

Sin embargo, considero que dentro de la biología tenemos algunos conceptos que, al ser abordados en la escuela, tienen un peso ético mayor que otros, y un caso particular se trata del cuerpo humano. Al igual que la célula, son muchas las formas en que los cuerpos humanos se presentan en diferentes contextos socioculturales, donde también influyen las percepciones y emociones de los sujetos. Asumir un modelo de cuerpo humano como una identidad orgánica única que puede representar a todos los seres humanos es un problema ético. Principalmente, cuando reconocemos que ese modelo que construimos de cuerpo humano normalmente se encaja con un padrón racial, de clase, de no discapacidad, de género y orientación sexual. Tal vez no se 
deba enseñar el tema cuerpo humano, y sí, los cuerpos humanos. O por lo menos arriesgarnos a construir esas otras posibilidades en las experiencias pedagógicas y en la investigación sobre enseñanza de conceptos biológicos.

Reconozco que para abordar las cuestiones de género y sexualidad de una forma no conservadora y excluyente tendremos muchos inconvenientes institucionales y familiares, muchos de ellos relacionados a la religión y otras creencias. Me permito cuestionar por qué la enseñanza de la biología asume una posición casi unánime cuando se trata de enseñar conceptos de evolución, defendiendo que es un concepto importante de ser enseñado y que es un derecho de los sujetos aprender sobre ello (aspectos que defiendo totalmente), a pesar de la alta oposición de algunas religiones a su enseñanza. Sin embargo, cuando se trata de cuestiones de género y sexualidad, no se tiene ese mismo pensamiento, esa misma fuerza, o, como prefiero llamarle, esa misma voluntad política de investigadoras/es en didáctica, formuladoras/es del currículo, profesoras/es. El obstáculo de la ideología conservadora religiosa parece suficiente para silenciar esos asuntos en muchos contextos escolares. Aspecto que también se debe, en parte, a la falta de abordaje de esos temas en la formación inicial del/a profesor/a de biología.

Finalizo realizando la invitación a docentes, investigadoras/es de la enseñanza y didáctica de las ciencias naturales, agentes de las políticas de enseñanza de la biología en el país y estudiantes, a que se interesen por la investigación por estos temas, por informarse y prepararse para abordar asuntos de género y sexualidad en la escuela desde diversas perspectivas y a que divulguen sus prácticas y hallazgos para fortalecer la comunidad académica sobre el asunto, principalmente en Colombia (y en general, en América Latina), una nación donde el fantasma de la ideología de género es usado como una herramienta para (des)orientar la opinión de todo un pueblo sobre cuál presidente escoger, o incluso, votar a favor o en contra de un acuerdo de paz.

\section{Referencias}

ALBUQUERQUE, Durval. "Por uma história acre: saberes e sabores da escrita da historiografia". In: ALBUQUERQUE, Gerson; ISHII, Raquel (org.). Desde as Amazônias: colóquios. Volume 2. Rio Branco: Nepan, 2014. p. 113-138.

ALBUQUERQUE, Gerson. "Acre”. In: ALBUQUERQUE, Gerson; PACHECO, Agenor. Uwa'kürü dicionário analítico. Rio Branco: Nepan Editora, 2016. p. 13-29.

BUTLER, Judith. Bodies that matter. On the discursive limits of sex. New York: Routledge, 1993.

CAETANO, Marcio; GOULART, Treyce; SILVA, Marlon. "Ensaio sobre a heteronormatividade: Modos curriculares de aprendizagem das sexualidades e do gênero". Atos de pesquisa em educação, Blumenau, v. 11, n. 2, p. 634-655, 2016.

CARDONA, Deisy; ARIZA, Alejandra; GAONA, Cindy; MEDINA, Óscar. "Conocimientos sobre sexualidad en adolescentes escolares en la ciudad de Armenia, Colombia". Revista Archivo Médico de Camagüey, Camagüey, v. 19, n. 6, p. 568-576, 2015.

COSTA, Paula; CORPES, Joanalira; SILVA, Elenita; VILAÇA, Teresa. "O ensino de biologia e suas articulações com as questões de corpos, gêneros e sexualidades". Bio-grafía. Escritos sobre la Biología y su enseñanza [En línea]. Bogotá, v. 9, n. 16, p. 77-86, 2016. Disponible en http:// revistas.pedagogica.edu.co/index.php/bio-grafia/article/view/4500. https://doi.org/10.17227/ 20271034.vol.9num. 16bio-grafia77.86. Acceso el 23/03/2018.

DALL'ORTO, Giovanni. "Mediterranean Homosexuality". In: WAYNE, Dynes. Encyclopedia of Homosexuality. New York: Garland, 1990. p. 796-798.

DÍAZ, Gabi; MORGADE, Graciela; ROMÀN, Cecilia. "Currículo, género y sexualidades según las Ciencias Biológicas escolares”. Revista de Educación en Biología, Córdoba, v. 14, n. 2, p. 30-35, 2011.

FOUCAULT, Michel. História da sexualidade l: A vontade de saber. Trad. ALBUQUERQUE, Maria Thereza; ALBUQUERQUE, Guilhon. Rio de Janeiro: Edições GRAAL, 1999.

GROSFOGUEL, Ramón. "Para descolonizar os estudos de economia política e os estudos póscoloniais: transmodernidade, pensamento de fronteira e colonialidade global". Trad. FERREIRA, Inês Martins. Revista Crítica de Ciências Sociais [En línea]. Coimbra, n. 80, p. 115-147, 2008. Disponible en https://journals.openedition.org/rccs/697. 10.4000/rccs.697. Acceso el 16/03/2018.

JARAMILLO, Claudia; SERRATO, Deysi. "El cuerpo como punto singular de la sexualidad: entre la normalización y otras posibilidades". Bio-grafía. Escritos sobre la Biología y su enseñanza [En 
línea]. Bogotá, v. 9, n. 16, p. 47-60, 2016. Disponible en http://revistas.pedagogica.edu.co/index.php/ bio-grafia/article/view/4498. https://doi.org/10.17227/20271034.vol.9num.16bio-grafia47.60. Acceso el 23/03/2018.

LOURO, Guacira. "Currículo, Gênero e sexualidade: o 'normal', o 'diferente' e o 'excêntrico'”. In: LOURO, Guacira; FELIPE, Jane; GOELLNER, Silvana (Orgs.). Corpo, Gênero e Sexualidade: um debate contemporâneo. 5. ed. Petrópolis: Vozes, 2010. p. 41-52.

LUISI, Verónica. Educación de la sexualidad en el contexto familiar y escolar. Educere, Santiago de Chile, v. 17, n. 58, p. 429-435, 2013. Disponible en http://www.saber.ula.ve/bitstream/handle/ 123456789/38384/articulo5.pdf?sequence=1 \&isAllowed=y. Acceso el 26/10/2018.

MEINARDI, Elsa. "Educación integral para las sexualidades". Bio-grafía. Escritos sobre la Biología y su enseñanza, Bogotá, v. 9, n. 16, p. 17-20, 2016.

MORGADE, Graciela. "Políticas de educação sexual integral: Saberes, práticas e corpos em tensão". Retratos da Escola, Brasília, v. 9, n. 16, p. 63-71, 2015.

MORGADE, Graciela (Coord.). Toda educación es sexual: hacia una educación sexuada justa. Buenos Aires: La Crujía, 2011.

MUKHERJEE, Siddhartha. The gene: An intimate History. New York: Simon and Schuster, 2016.

PELÚCIO, Larissa. "Subalterno quem, cara pálida? Apontamentos às margens sobre póscolonialismos, feminismos e estudos queer". Contemporânea [En línea]. São Carlos, v. 2, n. 2, p. 395-418, 2012. Disponible en http://www.contemporanea.ufscar.br/index.php/contemporanea/ article/viewFile/89/54. ISSN-e 2316-1329. Acceso el 23/03/2018.

PÉREZ, Eulalia. De la biología imaginaria a la sociología real: obstáculos para el acceso de las mujeres a la ciencia. Madrid: Ed. Complutense, 1996.

PLAZA, María; GONZÁLEZ, Leonardo; MEINARDI, Elsa. "La reflexión metacognitiva como estrategia para trabajar las creencias de sexualidad y género en la formación docente". Revista del IICE [En línea]. Buenos Aires, v. 38, p. 63-74, 2015. Disponible en http://revistascientificas.filo.uba.ar/index.php/ iice/article/view/3461. ISSN 2451-5434 10.34096/riice.n38.3461. Acceso el 23/03/2018.

PRECIADO, Beatriz. Testo Yonqui. Barcelona: Espasa Calpe, 2008.

PUGLIESE, Joseph; STRYKER, Susan. "The somatechnics of race and whiteness". Social Semiotics, London, v. 19, n. 1, p. 1-8, 2009.

ROA, Paola; OSORIO, Angélica. "Problematización de la Educación Sexual: Reflexiones acerca de la sexualidad en la Escuela Colombiana”. Bio-grafía. Escritos sobre la Biología y su Enseñanza, Bogotá, v. 9, n. 16, p. 23-29. 2016.

SANTOS, Sandro; ARAUJO, Ronaldo. "Corpos que ensinam e (des)organizam o discurso biológico: reflexões e diálogos na formação inicial de professores/as de Ciências e Biologia". In: ENCONTRO REGIONAL DE ENSINO DE BIOLOGIA SBEnBio REGIONAL4 - MG GO TO DF, 3, Juiz de Fora/MG, 2015. Anais...

SILVA, Elenita. "Tecendo percursos para pensar o corpo". In: REUNIÃO ANUAL DA ANPED, 34, Natal/RN, 2014. Anais....

Yonier Alexander Orozco Marin (apmusicomano@gmail.com) es Licenciado en Biología por la Universidad Distrital Francisco José de Caldas (Bogotá, Colombia). Concluyó la Maestría en Enseñanza de las Ciencias y las Matemáticas por la Universidad Federal del Acre (Rio Branco, Acre, Brasil). Actualmente realiza el Doctorado en Educación Científica y Tecnológica por la Universidad Federal de Santa Catarina (Florianópolis, SC, Brasil). 


\section{COMO CITAR ESTE ARTíCULO, DE ACUERDO CON LAS NORMAS DE LA REVISTA:}

MARIN, Yonier Alexander Orozco. "Problematizando el discurso biológico sobre el cuerpo y género, y su influencia en las prácticas de enseñanza de la biología”. Revista Estudos Feministas, Florianópolis, v. 27, n. 3, e56283, 2019.

\section{CONTRIBUCIÓN DE AUTORÍA}

No aplicable.

\section{FINANCIACIÓN}

No aplicable.

\section{CONSENTIMIENTO DE USO DE IMAGEM}

No aplicable.

\section{APROBACIÓN DE COMITÉ DE ÉTICA EN INVESTIGACIÓN}

No aplicable.

\section{CONFLICTO DE INTERESES}

No aplicable.

\section{LICENCIA DE USO}

Este artículo está licenciado bajo la Licencia Creative Commons CC-BY Internacional. Con esta licencia se puede compartir, adaptar, crear material para cualquier objetivo, siempre que se le atribuya la autoría.

\section{HISTORIAL}

Recebido em 09/04/2018

Reapresentado em 09/11/2018

Aprovado em 04/04/2019 